\title{
SURFACE STRUCTURES OF NEW AND LESSER KNOWN SPECIES OF THERMOBIFIDA AS REVEALED BY SCANNING ELECTRON MICROSCOPY*
}

\author{
J. KuKOLYA, L. SZABÓ and L. HoRNOK** \\ Szent István University and Agricultural Biotechnology Center, \\ H-2101 Gödöllö, P. O. Box 411, Hungary
}

(Received: August 31, 2000; accepted: October 5, 2000)

\begin{abstract}
Surface structures of representatives of the genus Thermobifida were examined by scanning electron microscopy. Spores formed at the tips of multibranched sporophores initially resembled short sausages; then, upon maturation, they gradually built up their typical ovoid shape. Characteristic differences were observed between T. cellulolytica strain TB108 and T. fusca strains TM51. The spores of TB108 were larger $(0.8 \times 1.3 \mu \mathrm{m})$ than those of TM51 $(0.6 \times 1.1 \mu \mathrm{m})$ in consequence of the more thickened outer squamous layer. When Thermobifida strains were grown on cellulose as sole carbon source, the mycelium was found to coil around the cellulose crystals and multiple protuberances emerged, resulting in a scabrous appearance to the mycelial surface. The presence of these cellulosome-like structures yielded a $24.5 \%$ surface enlargement of the scabrous mycelium as compared with the smooth one. The cellulosome emergence pattern paralleled the proportional increase in free endoglucanase activity measured during the culturing of these actinomycetes in the presence of cellulose.
\end{abstract}

Keywords: Thermobifida - sporogenesis - scanning electron microscopy - cellulosome - endoglucanase activity

\section{INTRODUCTION}

Thermophilic aerobic actinomycete strains that form single spores on aerial mycelium and frequently occur in heating plant biomass were originally affiliated by Henssen into the genus Thermomonospora [5]. Further actinomycetes were subsequently assigned to the genus and the ninth edition of Bergey's Manual of Determinative Bacteriology has already accepted six species within this group of prokaryotes [12]. On the basis of phylogenetic, chemotaxonomic and phenotypic evidence, the genus has recently been reclassified [18] and a new genus, named Thermobifida, has been constructed to group together the real cellulolytic thermophiles in a distinct taxon. Only two species are at present assigned to this genus, Thermobifida alba and T. fusca. Both organisms are Gram-positive, chemo-organotrophic and non-acid-fast, with a cell wall containing meso-DAP (cell wall type III).

\footnotetext{
*Dedicated to Professor Lajos Ferenczy on the occasion of his 70th birthday.

**Corresponding author; e-mail: hornok@abc.hu
} 
Their sugar, phospholipid and fatty acid patterns are of type $\mathrm{C}$ (no diagnostic sugar), type II (phosphatidylethanolamine, glycolipid) and type 3e (10 methyl-17:0- and iso16:0-branched fatty acids are predominant). The members of the genus Thermobifida are ecologically important organisms comprising one of the most active groups of lignocellulose-decomposing bacteria producing multiple cellulases, xylanases and lignolytic enzymes $[2,7,11]$.

We earlier isolated a number of thermotolerant and thermophilic actinomycete strains from the hot region of composted horse manure. All of them were capable of hydrolyzing soluble, microcrystalline and crystalline cellulose, as well as xylan, gelatin and the surfactant Tween 80 . These prokaryotes could grow on straw as sole carbon source, although their lignin-solubilizing activities varied greatly. The temperature ranges required for growth of the strains were between 27 and $69{ }^{\circ} \mathrm{C}$. The traditional determination traits led to these thermophilic actinomycetes being identified as Thermomonospora alba, T. fusca and T. spp. [8].

When the revision of the genus Thermomonospora became accepted, we re-examined the whole thermophilic actinomycete collection of our laboratory and confirmed that these strains really do belong in one or other species of the Thermobifida, namely T. fusca. However, although some of the isolates exhibited morphological and biochemical characteristics typical of Thermobifida, they could not be assigned into either of the two known species of the genus. These isolates were therefore subjected to chemotaxonomic investigations and $16 \mathrm{~S}$ rDNA sequence analysis. The molecular traits revealed by these examinations resulted in their classification as representatives of a new species, under the name Thermobifida cellulolytica sp. nov. [9].

There have been a few investigations of the fine structure morphology of these thermophilic actinomycetes, and they have been limited to Thermobifida (Thermomonospora) fusca [4]. Ultrastuctural data allowing comparisons of species or strains within this group of aerobic thermophiles are lacking. The aim of the present study, therefore, was to compare the scanning electron microscopic surface ornamentation of representatives of two species of Thermobifida, T. cellulolytica and T. fusca. The ultrastructural changes that occurred upon induction of the cellulase systems of these organisms were also determined.

\section{MATERIALS AND METHODS}

\section{Culturing procedures}

The actinomycete strains used in these experiments, T. cellulolytica TB108 and T. fusca TM51 have been deposited in the culture collection of the Department of Microbiology, Szent István University, Gödöllö [8]. They were cultivated on a basal medium containing $\mathrm{NaNO}_{3} 1 \mathrm{~g}, \mathrm{KCl} 0.3 \mathrm{~g}, \mathrm{MgSO}_{4} \times \mathrm{H}_{2} \mathrm{O} 0.5 \mathrm{~g}, \mathrm{~K}_{2} \mathrm{HPO}_{4} 1 \mathrm{~g}$, yeast extract (Sigma, St. Louis, USA) $0.5 \mathrm{~g}$, peptone (Sigma) $0.5 \mathrm{~g}$, and distilled water 11 (pH 7.6) at $50^{\circ} \mathrm{C}$. MN 300 cellulose powder (Machery Nagel, Düren, Germany) 
$\left(10 \mathrm{~g}^{-1}\right)$, carboxymethyl cellulose (Sigma) $\left(10 \mathrm{~g} \mathrm{l}^{-1}\right)$ or glucose $\left(5 \mathrm{~g} \mathrm{l}^{-1}\right)$ was added as carbon source to this solution. Solid media were prepared by adding $20 \mathrm{~g} \mathrm{l}^{-1}$ agar (Reanal, Budapest, Hungary).

\section{Scanning electron microscopy}

For scanning electron microscopy, cultures were grown on basal medium containing MN 300 cellulose powder at $55^{\circ} \mathrm{C}$ under saturated humidity for 4 days. Sporulating colonies were scraped off the agar surface with a scalpel and small sections of these colonies were stuck onto the grids by means of low melting point agarose. The specimens were fixed according to Bozzola et al. [3] with minor modifications. The grids with the adherent specimens were placed overnight in $0.5 \mathrm{M}$ cacodylate buffer containing $2 \%(\mathrm{w} / \mathrm{v})$ glutaraldehyde and dehydrated in a serial dilution of acetone $(25-100 \%)$. Specimens were preserved by critical point drying in Baltec CDP 030 equipment (Baltec AG, Neugrüt, Liechtenstein) in liquid $\mathrm{CO}_{2}$ at 50 bar. They were then gold-coated by using a Baltec SCD 005 sputter coaster (Baltec AG). Preparations were examined with a Zeiss EM910 electron microscope at $40 \mathrm{kV}$, recorded digitally and video-printed with a Mitsubishi P78E recorder (Mitsubishi Electric Co., Tokyo, Japan). The dimensions of the actinomycete structures were measured by using the Pro 3.00 software analySIS package (Soft Imaging System GmbH, Münster, Germany).

\section{Determination of endoglucanase activity}

Endoglucanase activity was measured by a viscosimetric method according to Whitney [17]. The reaction mixture, containing $1 \mathrm{ml}$ of culture supernatant (or whole culture suspension) and $4 \mathrm{ml}$ of $0.5 \%(\mathrm{w} / \mathrm{v})$ carboxymethyl cellulose solution, was incubated at $37{ }^{\circ} \mathrm{C}$. Incubation was stopped after $2,5,10,15$ or 20 minutes by adding $100 \mathrm{ml}$ of $1 \%(\mathrm{w} / \mathrm{v}) \mathrm{HgCl}_{2}$ solution. The decrease in relative viscosity was determined with an Oswald viscosimeter and the results were graphically analyzed. One unit of enzyme activity was equivalent to a $50 \%$ decrease in relative viscosity after incubation for $10 \mathrm{~min}$.

\section{RESULTS AND DISCUSSION}

\section{Spore morphology}

The members of the genus Thermobifida produce single aleuriospores on extensively branched non-fragmenting aerial hyphae. The sporophores may be simple or abundantly branched. Repeated sporophore branching results in dense clusters of spores endowing the colonies with a mealy surface (Fig. 1). The spores formed at the tips of 


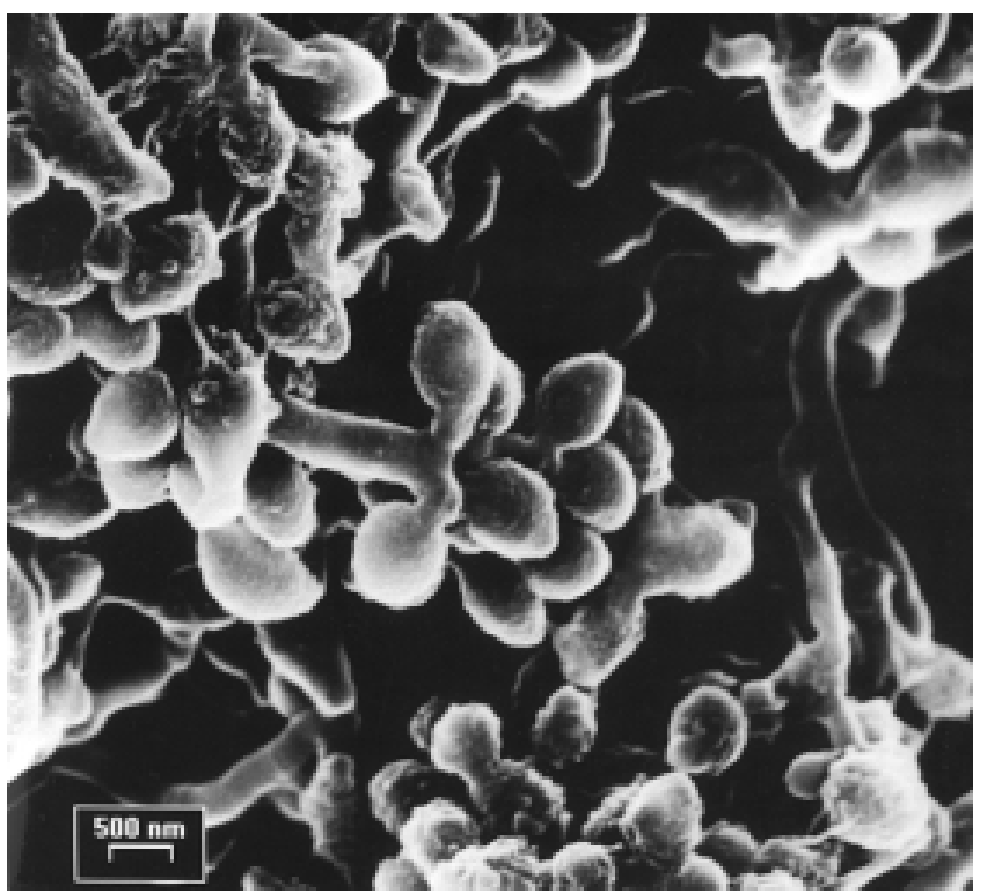

Fig. 1. Spore cluster development on multibranched sporophores of Thermobifida fusca strain TM51

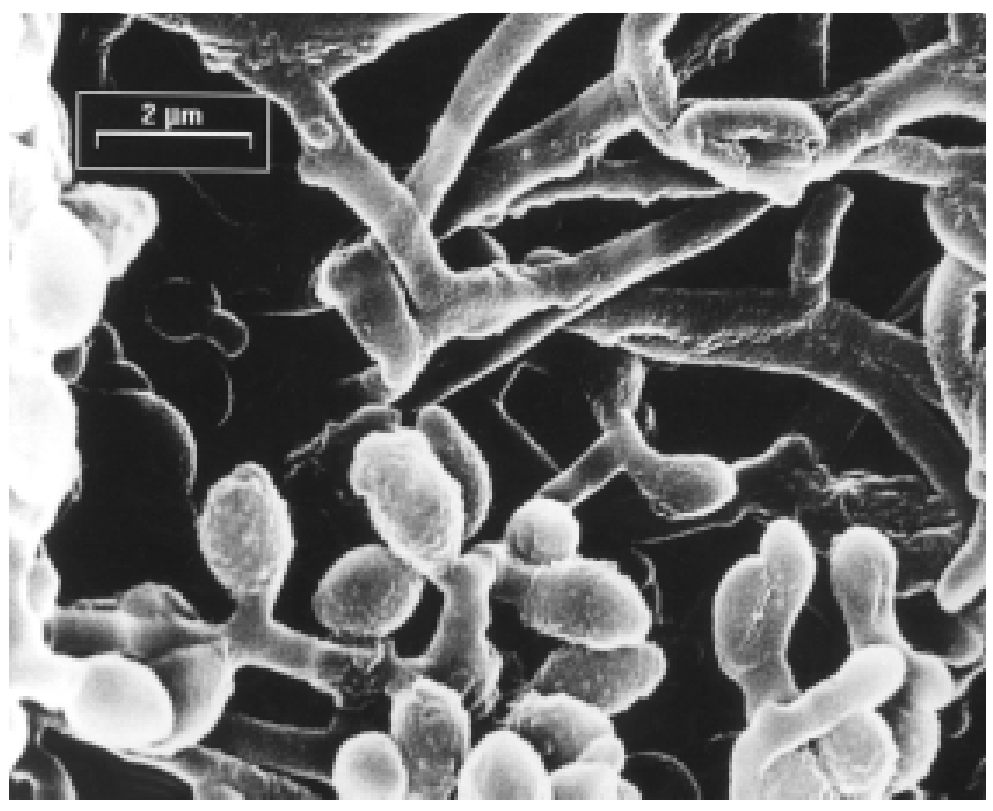

Fig. 2. Sporogenesis of Thermobifida fusca strain TM51 


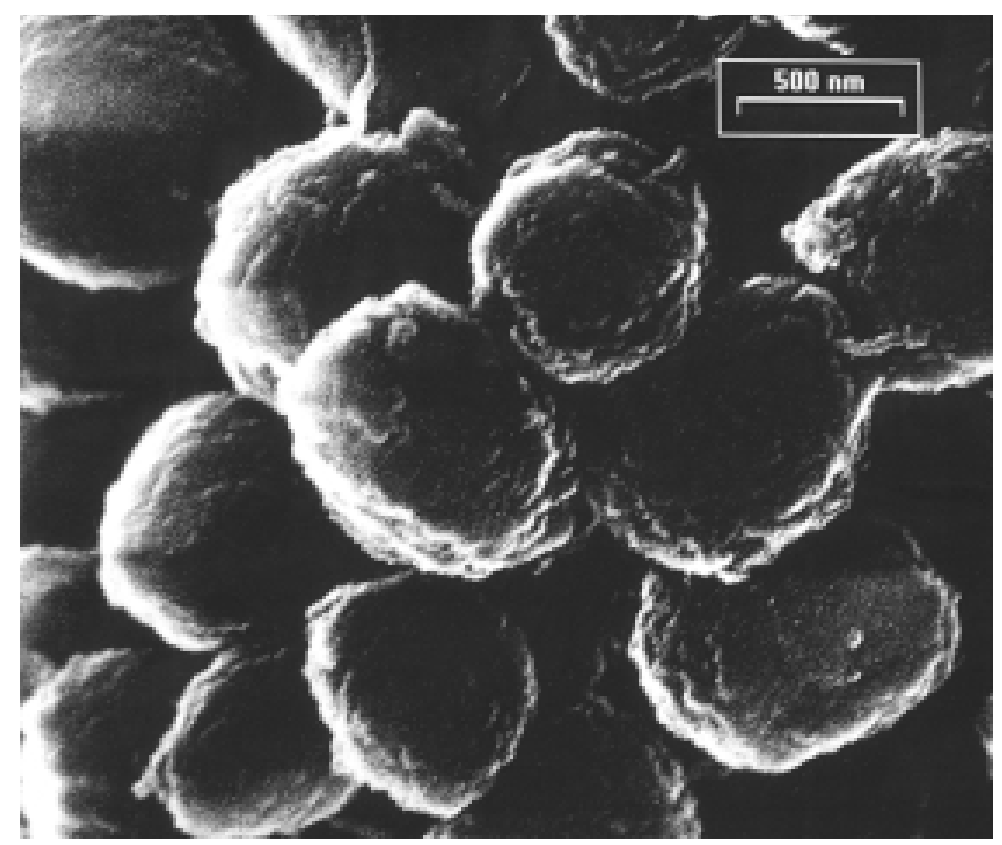

Fig. 3. Spore surface ornamentation of Thermobifida fusca strain TM51

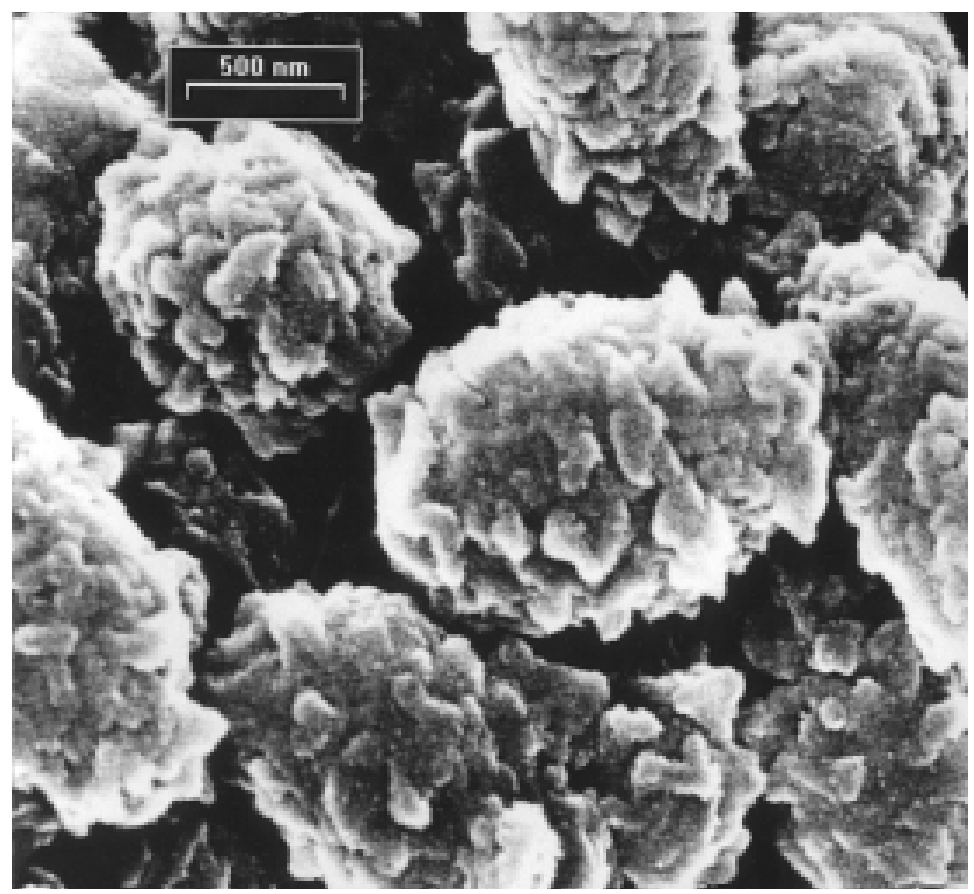

Fig. 4. Spore surface ornamentation of Thermobifida cellulolytica strain TB108 
the sporophores initially resemble short sausages, as can be seen in Fig. 2, right, below; then, upon maturation, they gradually build up their characteristic ovoid shape.

On superficial examination, the spore surface looked smooth, corresponding to previous observations on Thermomonospora fusca [12] and to the original description of the genus Thermobifida [18]. However, high-resolution scanning electron microscopy revealed a typical squamous surface, resembling a pine-cone. This squamous structure was found to be more distinct in mature spores than in young ones. Early electron microscopic observations on T. fusca [4] led to this outer layer of the spores being described as a globular or tubercular surface. These structures, however, were artifacts due to the inadequate fixation technologies; the limited resolving power of scanning electron microscopy some 25 years ago did not reveal this technical weakness.

Slight but consistent differences were observed between strains TB108 and TM51 the representatives of $T$. fusca and T. cellulolytica, respectively (Figs 3 and 4). The spores of TB108 were larger $(0.8 \times 1.3 \mu \mathrm{m})$ than those of TM51 $(0.6 \times 1.1 \mu \mathrm{m})$ in consequence of the more thickened outer squamous layer that covered the former. However, these differences are not of descriptive value at a species level because of the considerable interstrain variability detected when other isolates of these two species were subjected to scanning electron microscopy.

\section{Cellulosome-like structures on the surface of T. fusca mycelia}

When T. fusca TM51 was grown on basal medium containing glucose as a sole carbon source, the mycelial surface of the actinomycete was found to be smooth (Fig. 5a). However, when this bacterium was grown on cellulose, the mycelium coiled tightly round the cellulose crystals and the digestion activity exerted by the cellulase system caused deep furrows on the substrate (Fig. 6). Higher magnification revealed an altered surface topology of the mycelium. As shown in Fig. 5b, multiple protuberances emerged on the surface, giving the mycelium a scabrous appearance. These hemispheric protuberances had an average diameter of $69 \mathrm{~nm}$ (Fig. 5c) and appeared to be similar to the cellulosomes described first by Lamed et al. [10] in Clostridium thermocellum. Cellulosome-like structures have also been observed on the mycelium surface of Thermomonospora curvata cultivated on cellulose, xylan [6] or cellobiose [15].

Cellulosomes are considered to harbor complex cellulase systems and provide both physical and chemical adhesion factors that promote the tight adhesion of the actinomycete to insoluble polymeric substrates $[1,16]$. The presence of cellulosomes additionally contributes to a significant increase in the surface area, providing ordered sites for the synergistic interaction of the multiple cellulases [14] and improving the efficiency of nutrient transport [1]. We calculated the average number of cellulosomes per $\mu \mathrm{m}^{2}$ of surface area of T. fusca hyphae to be 64. If these structures are presumed to form a normal hemisphere (which in fact they do), their pres- 

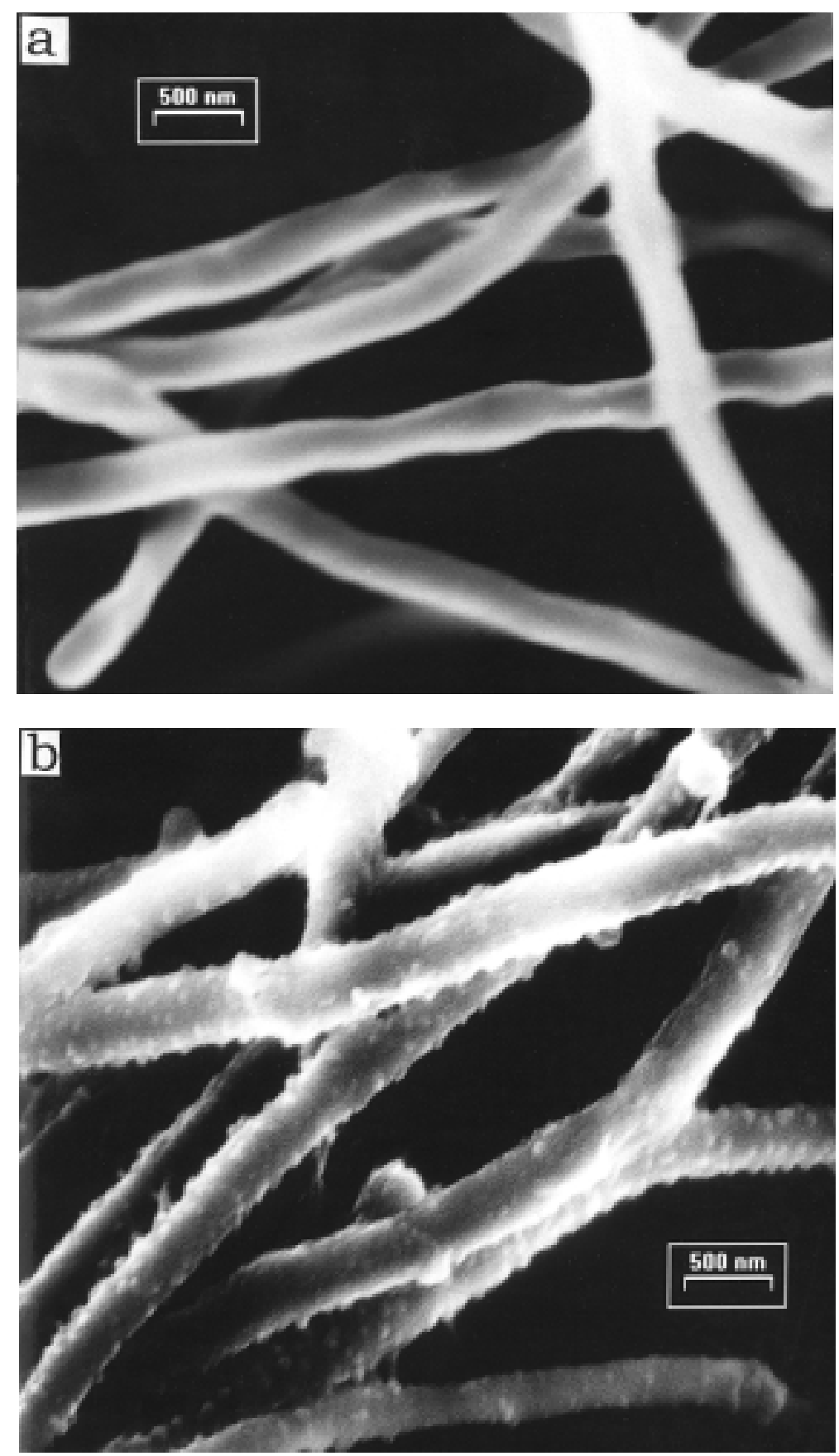

Fig. 5 


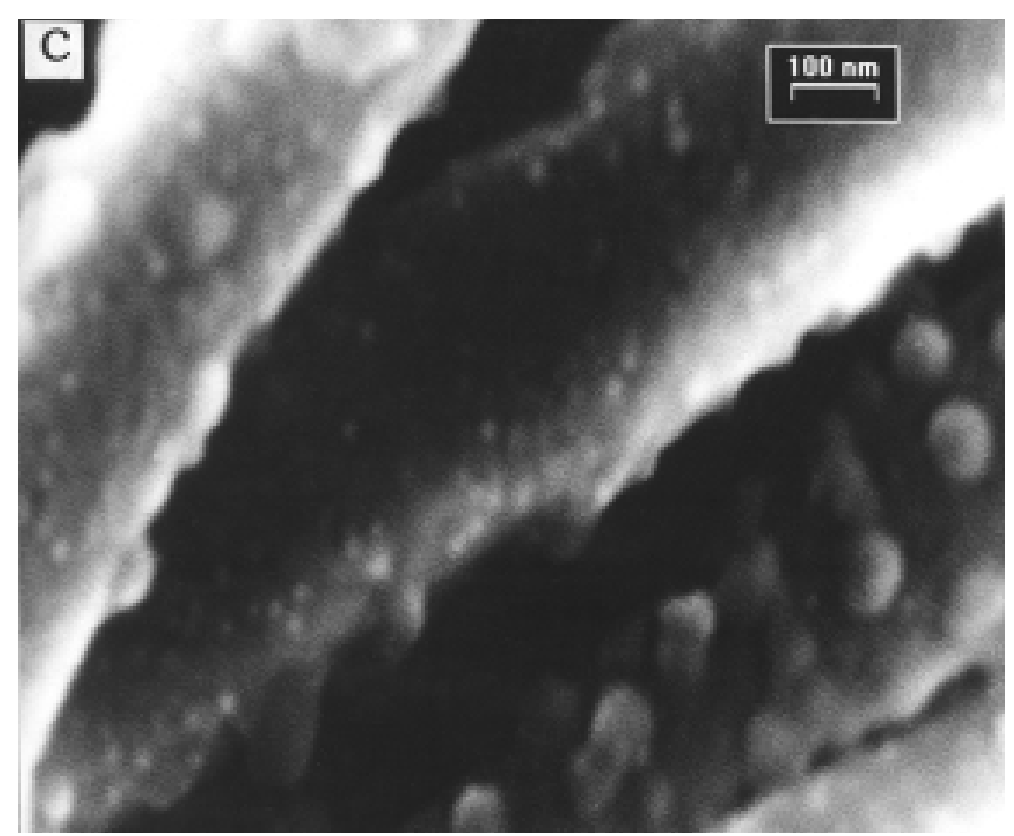

Fig. 5. Hyphal surface of Thermobifida fusca TM51. (a) Smooth surface of mycelium grown on glucose as carbon source. (b) Cellulosome-like structures emerged upon induction by cellulose. (c) Morphology of cellulosomes shown by higher magnification

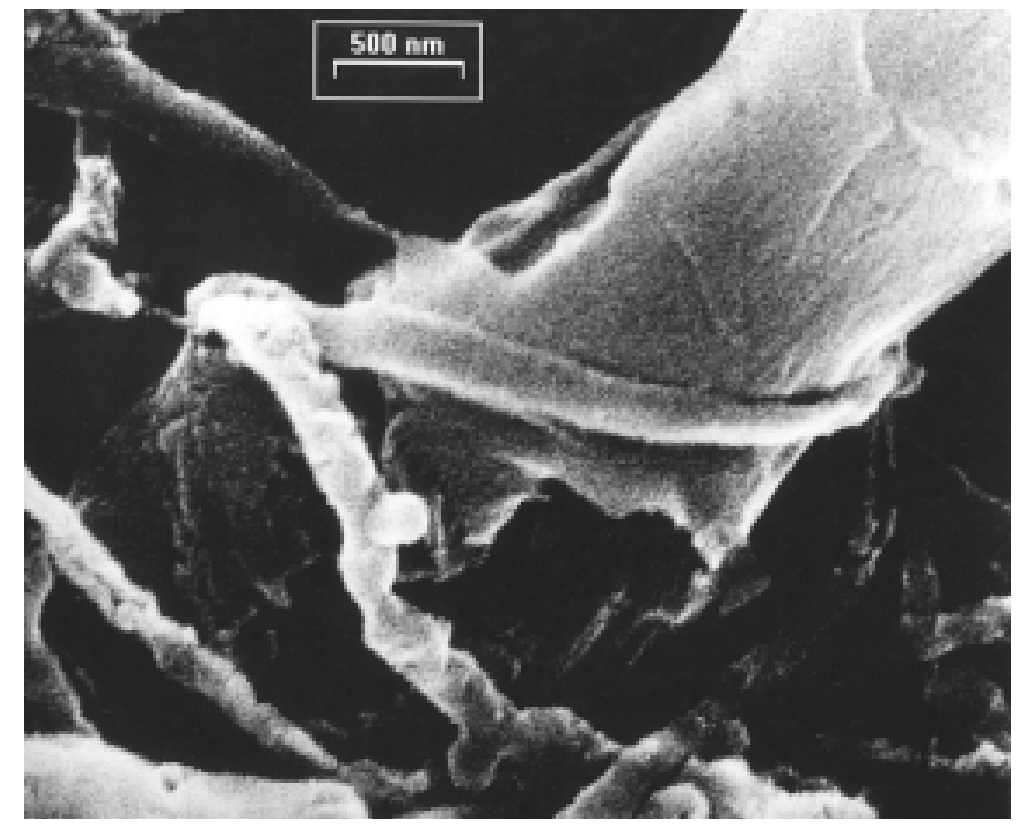

Fig. 6. Thermobifida cellulolytica mycelium coiling around cellulose crystals 


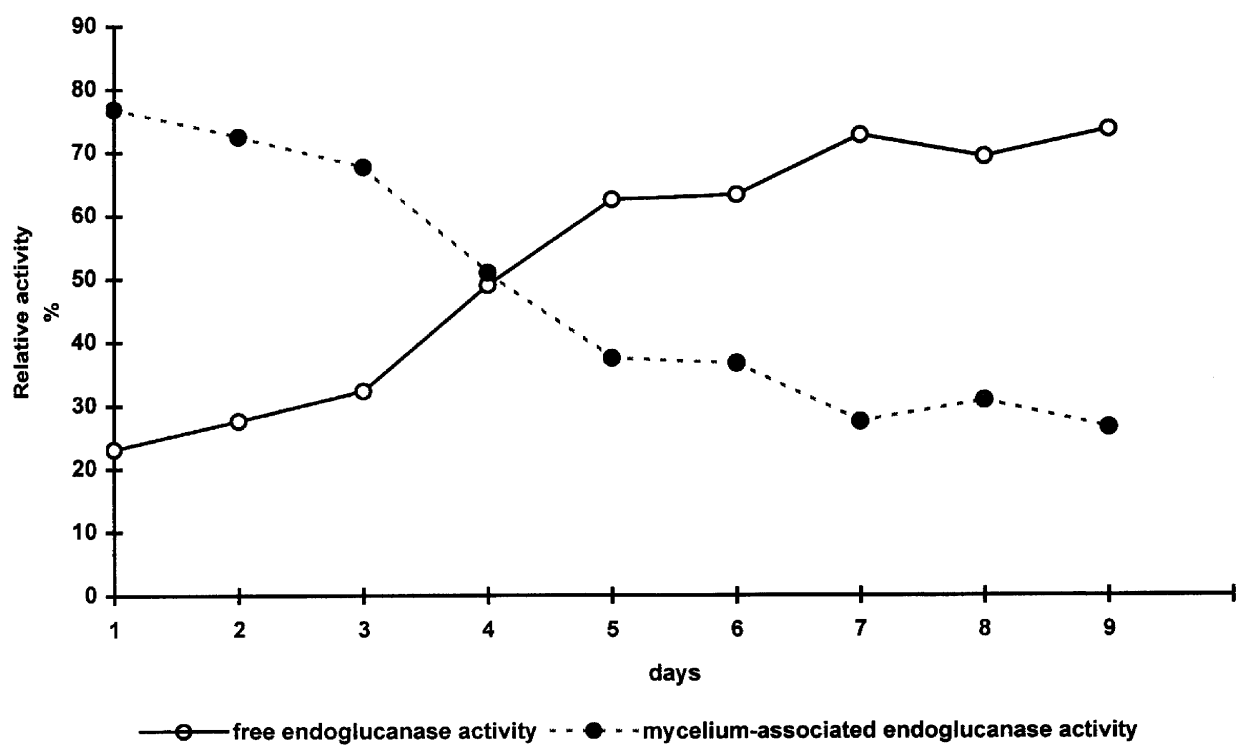

Fig. 7. Comparison of free and mycelium-associated endoglucanase activities during the culturing of Thermobifida fusca TM51 on cellulose as sole carbon source

ence results in a $24.5 \%$ surface enlargement of the scabrous mycelium as compared with the smooth one.

T. fusca TM51 was grown as a shaken culture on basal medium containing carboxymethyl cellulose as sole carbon source. Suspension samples were taken at 24-h intervals and endoglucanase activities were determined by viscosimetry. Three subsamples were subjected to endoglucanase measurements. The total endoglucanase activity was determined by measuring the enzyme activity in the whole suspension sample, comprising the substrate, the mycelial mat and the soluble fraction of the medium. Free (soluble) endoglucanase activity and mycelium-associated activity were determined in the culture supernatant and the sediment, respectively, obtained after centrifugation at 5000 r.p.m. for 10 min. Figure 7 presents a graphic comparison of the free and the mycelium-associated endoglucanase activities.

The cellulosome emergence pattern followed the proportional increase in free endoglucanase activity. These structures became apparent on the second day of culturing; they increased in both number and size during the next $48 \mathrm{~h}$, remained in a constant state for an additional 2 days of cultivation, and then gradually disappeared. This pattern of cellulosome development was paralleled by a progressive increase in free endoglucanase activity that occurred at the expense of the mycelium-associated activity. The free endoglucanase activity involves enzymes liberated from the cell surface after proteolytic cleavage [13], whereas the mycelium-associated activity is due to large, membrane-bound complex enzyme molecules. 
By means of scanning electron microscopy, we demonstrated that the squamous spore surface is typical of the actinomycetes belonging in the genus Thermobifida. All strains investigated to date display these structures and the minor differences observed in the shapes and sizes of the spores are not suitable for a differentiation between the known species of this group of prokaryotes. Further investigations on the surface structures of representatives of Thermobifida revealed for the first time the presence of cellulosomes, which emerged on the mycelial surface upon induction of the cellulase complex in these organisms.

\section{ACKNOWLEDGEMENT}

This work was supported by grants from OTKA (T 32407) and FKFP (0315/99).

\section{REFERENCES}

1. Bayer, E. A., Lamed, R. (1986) Ultrastructure of the cell surface cellulosome of Clostridium thermocellum and its interaction with cellulose. J. Bacteriol. 167, 828-836.

2. Blanco, J., Coque, J. J., Velasco, J., Martin, J. F. (1997) Cloning, expression in Streptomyces lividans and biochemical characterization of a thermostable endo-beta-1,4-xylanase of Thermomonospora alba ULJB1 with cellulose-binding ability. Appl. Microbiol. Biotechnol. 48, 208-217.

3. Bozzola, J. J., Russel, L. D. (1992) Specimen preparation for scanning electron microscopy. In: J. J. Bozzola, L. D. Russel (eds) Electron Microscopy. Jones and Bartlett Publishers, London, pp. 40-64.

4. Crawford, D. L., Gonda, M. A. (1977) The sporulation process in Thermomonospora fusca as revealed by scanning and transmission electron microscopy. Can. J. Microbiol. 23, 1088-1095.

5. Henssen, A. (1957) Beiträge zur morphologie und systematik der thermophilen actinomyceten. Arch. Microbiol. 26, 373-414.

6. Hostalka, F., Moultrie, A., Stutzenberger, F. (1992) Influence of carbon source on cell surface topology of Thermomonospora curvata. J. Bacteriol. 174, 7048-7052.

7. Kleeberg, I., Hetz, C., Kroppenstedt, R. M., Muller, R. J., Deckwer, W. D. (1998) Biodegradation of aliphatic-aromatic copolyesters by Thermomonospora fusca and other thermophilic compost isolates. Appl. Environ. Microbiol. 64, 1731-1735.

8. Kukolya, J., Dobolyi, C., Hornok, L. (1997) Isolation and identification of thermophilic cellulolytic actinomycetes. Acta Phytopath. Entomol. Hung. 32, 97-107.

9. Kukolya, J., Láday, M., Halbritter, A., Oravecz, O., Márialigeti, K., Hornok, L. (2000) Thermobifida cellulolytica sp. nov., a new lignocellulose decomposing member of the genus Thermobifida. Proceedings of the General Assembly of the Hungarian Society for Microbiology, Keszthely, 63 p.

10. Lamed, R., Naimark, J., Morgenstern, E., Bayer, E. A. (1987) Specialized cell surface structures in cellulolytic bacteria. J. Bacteriol. 169, 3792-3800.

11. Lao, G., Gurdev, S., Ghangas, G. S., Jung, E. D., Wilson, D. B. (1991) DNA sequences of three $\beta$ 1,4-endoglucanase genes from Thermomonospora fusca. J. Bacteriol. 173, 3397-3407.

12. McCarthy, A. J. (1989) Thermomonospora and related genera. In: S. T. Williams, M. E. Sharpe, J. G. Holt (ed.) Bergey's Manual of Systematic Bacteriology, Vol. 4. Williams and Wilkins, Baltimore, pp. 2552-2572.

13. Schlochtermeier, A., Niemeyer, F., Schrempf, H. (1992) Biochemical and electron microscopic studies of the Streptomyces reticuli cellulase (avicelase) in its mycelium-associated and extracellular forms. Appl. Environ. Microbiol. 58, 3240-3248.

14. Spiridonov, N. A., Wilson, D. B. (1998) Regulation of biosynthesis of individual cellulases in Thermomonospora fusca. J. Bacteriol. 180, 3529-3532. 
15. Stutzenberger, F. J. (1991) Cellulose degradation by thermophilic aerobic bacteria. In: C. H. Haigler, P. J. Weimer (eds) Biosynthesis and Biodegradation of Cellulose. Marcel Dekker, New York, pp. $445-490$

16. Walter, S., Rohde, M., Machner, M., Schrempf, H. (1999) Electron microscopy studies of cell-wallanchored cellulose (Avicel)-binding protein (AbpS) from Streptomyces reticuli. Appl. Environ. Microbiol. 65, 886-892.

17. Whitney, P. J. (1982) Cellulase and pectinase induction and estimation. In: S. B. Primrose, A. C. Wardlaw (eds) Sourcebook of Experiments for the Teaching of Microbiology. Academic Press, New York, pp. 626-630.

18. Zhang, Z., Wang, Y., Ruan, J. (1998) Reclassification of Thermomonospora and Microtetraspora. Int. J. Syst. Bacteriol. 48, 411-422. 
